area and will have a tendency to recur, so that regular monitoring is required. Complete arrest of the progressive underlying degenerative process cannot be expected. Recent studies $^{16}$ have shown the importance of early treatment: $83 \%$ of patients who had had symptoms for two weeks or less were treatable, but after four and 12 months only $30 \%$ and $1 \%$ respectively of eyes had lesions still amenable to treatment.

In spite of the well-founded rationale of photocoagulation and the encouraging evidence, a randomised controlled trial has been judged necessary ${ }^{17}$ to assess the complication rate of the treatment itself, the proportion of patients with senile macular degeneration who go on to develop disciform lesions, and what proportion of these in turn are preventable.

Clearly treatment of this kind will place a further load on the ophthalmic services, which have not yet digested the problem of light coagulation for diabetic retinopathy. Regular assessment with intravenous fluorescein and fundus photography would be neither practicable nor worth while for monitoring all patients with senile macular degenerationunless disciform lesions are more common than clinical impression suggests. Nevertheless, if a disciform lesion occurs in one eye regular checks on the second with a view to treatment is a reasonable policy ${ }^{16}$ because $12 \%$ of second eyes become affected each year. ${ }^{18}$ Thereby we may prevent or postpone blindness in both eyes-a disaster of quite a different order from blindness in only one eye.

${ }^{1}$ Department of Health and Social Security, Blindness and Partial Sight in England, 1969-1976. Reports on Public Health and Medical Subjects, no 129. London, HMSO, 1979.

2 Gass, J D M, American fournal of Ophthalmology, 1967, 63, 573.

3 Gass, J D M, American fournal of Ophthalmology, 1967, 63, 587.

4 Gass, J D M, American fournal of Ophthalmology, 1967, 63, 617.

${ }^{5}$ Gass, J D M, American fournal of Ophthalmology, 1967, 63, 645.

${ }^{6}$ Gass, J D M, American Fournal of Ophthalmology, 1967, 63, 661.

7 Gass, J D M, American fournal of Ophthalmology, 1967, 63, 689.

8 Teeters, V W, and Bird, A C, American fournal of Ophthalmology, 1973, 75, 53.

9 Teeters, V W, and Bird, A C, American fournal of Ophthalmology, 1973, 76, 1 .

10 Schatz, H, and Patz, A, Archives of Ophthalmology, 1973, 90, 183.

11 Gass, J D M, Archives of Ophthalmology, 1973, 90, 206.

12 Bird, A C, British fournal of Ophthalmology, 1974, 58, 367.

13 Bonnet, M, Archives d'Ophtalmologie et Revue Générale d'Ophtalmologie, 1975, 35, 311.

${ }^{14}$ Hirose, T, Fapanese fournal of Clinical Ophthalmology, 1976, 30, 191.

15 Sand, A B, Acta Ophthalmologica, 1977, 55, 497.

16 Grey, R H B, Bird, A C, and Chisholm, I H, British fournal of Ophthalmology, 1979, 63, 85 .

17 Bird, A C, Transactions of the Ophthalmological Societies of the United Kingdom, 1978, 98, 303.

${ }^{18}$ Gregor, Z, Bird, A C, and Chisholm, I H, British fournal of Ophthalmology, $1977,61,141$.

\section{Treatment of tinnitus}

Tinnitus (from the latin tinnire, to tinkle) may be distinguished from sounds produced outside the auditory pathway by being non-pulsatile and often, but not always, continuous. Usually the patient likens the noise to some sound familiar to him-such as the noise heard when a sea shell is held close to the ear, escaping steam, whistling, blowing, crackling, or the noise of machinery. Sometimes there is a mixture of sounds. Tinnitus can never be heard by an observer, since it is purely subjective and is produced within the auditory system. Sounds of this kind occur in nearly all forms of ear disease, and are generally associated with a measurable degree of hearing loss, which may be conductive, sensorineural, or a combination of both. ${ }^{1}$
Tinnitus may be caused by a disturbance of any part of the auditory system, but the lesion is commonly peripheral. It may be trivial-wax in the meatus or a temporary malfunction of the eustachian tube-or there may be an underlying more serious disease-such as otosclerosis or Menière's disorder. In both Menière's disorder and in presbyacusis the tinnitus is frequently associated with distortion of hearing, indicating end-organ disease. Tinnitus may be the first warning of the onset of hearing loss induced by industrial noise or of ototoxicity from drugs such as streptomycin. Unilateral tinnitus requires full investigation, since it can be the first sign of an acoustic neuroma. ${ }^{2}$ Discrete lesions in certain parts of the temporal lobe of either side may cause noise heard in one or both ears. This may be an epileptic happening-the result of intermittent local discharge from the temporal lobe neurones around, for example, a tumour or infarct.

A sort of tinnitus is occasionally encountered in patients with no demonstrable hearing loss, when non-auditory lesions should be considered, including carious or impacted wisdom teeth, anaemia, and hypotension or hypertension. The intracranial, intraosseous, and extracranial blood vessels of the head and neck form a sound-producing system. Ordinarily we do not hear our blood circulation, but an aneurysm, an angioma, or a caroticocavernous fistula may give rise to sounds which may be heard with a stethoscope, and a meningioma may have such a rich blood supply that the noise it makes is obvious to others. The most common cause of pulsatile head noise is atheromatous stenosis of the arteries of the neck, especially at the origin of the two carotid arteries from the parent trunk. Pressure on the common carotid artery by a finger will alter or stop it and establish the diagnosis. ${ }^{1}$ Rapid contractions of the tensor tympani muscle may also produce audible tinnitus: this form of habit spasm is occasionally seen in children. More organised sounds such as voices or bells or definite musical sequences come under the heading of auditory hallucinations and are rare in ear disease, though common in psychiatric practice. ${ }^{3}$ Nevertheless, when patients are concerned that the noises they hear indicate mental derangement this is rarely the case.

Treatment of tinnitus is unsatisfactory, since the most common cause is degeneration of the organ of Corti, which is irreversible. What is important is that the patient should understand that the symptom, though unpleasant, does not indicate serious disease and that he or she can come to terms with it by a process of adaptation. Such an explanation about the cause of tinnitus and reassurance about its harmlessness will usually enable the patient to accept it, and the use of a masking tone in a specially designed hearing aid may be of value. Tranquillisers rarely help, but hypnotics may be useful at night.

Some patients, however, fail to come to terms with their tinnitus, which makes their lives intolerable. Recent work by Melding and Goodey ${ }^{4}$ has offered some prospect of treatment in such cases. Their earlier assessment of the effect of intravenous lignocaine on tinnitus in 78 patients had shown that it was highly effective in suppressing symptoms in patients with sensorineural hearing loss due to damage or degeneration of the organ of Corti but less effective in other groups. ${ }^{5}$ They assumed that this effect of lignocaine on tinnitus was due to its known anticonvulsant action, and postulated that the tinnitus was due to deafferentation of the auditory pathways leading to neuronal hyperactivity. In their latest study they assessed ${ }^{4} 125$ patients with incurable and intolerable tinnitus by a preliminary test with intravenous lignocaine $(1-2 \mathrm{mg} / \mathrm{kg}$ without adrenalin) given over three to four 
minutes. Those patients whose symptoms were relieved were offered treatment with carbamezapine in gradually increasing dosage until adequate concentrations were reached in about three weeks-usually $600-1000 \mathrm{mg}$ daily. Patients who showed allergy or intolerance to carbamezapine were treated with diphenylhydantoin in doses up to $400 \mathrm{mg}$ daily. This treatment proved successful, but after withdrawal of the drug the tinnitus slowly returned, so that it has to be given continuously with adequate monitoring of serum concentrations and toxic effects.

${ }^{1}$ Edwards, C H, Neurology of Ear, Nose and Throat Diseases. London, Butterworth, 1973.

2 Ballantyne, J C, and Groves, J, A Synopsis of Otolaryngology, 3rd edn. Bristol, John Wright, 1978.

${ }^{3}$ British Medical fournal, 1979, 1, 841.

4 Melding, P S, and Goodey, R J, fournal of Laryngology and Otology, 1979, 93, 111 .

5 Melding, P S, Goodey, R J, and Thorne, P R, fournal of Laryngology and Otology, 1978, 92, 115.

\section{Adolescent idiopathic scoliosis}

Over 40 years ago scoliosis occurring in otherwise healthy adolescents, particularly girls, was separated from the spinal curvatures of known cause. The latter included scoliosis associated with tuberculosis, neuromuscular disease, congenital vertebral anomalies, and other rarer causes. At first believed to be rachitic, adolescent scoliosis was later termed "idiopathic" since its aetiology was not known, and it was diagnosed only by eliminating all other possible causes. Moreover, the cause remains unknown today, though its frequency far exceeds that of all other forms of scoliosis put together.

Typically idiopathic scoliosis develops between 10 and 14 years of age, though it is often difficult to be precise about the time of onset. Occasionally the typical "adolescent" pattern of scoliosis may develop as early as the age of 6 . From the results of school screening programmes to determine the frequency of scoliosis it would appear that, if only very small curves are noted, then boys and girls are almost equally affected. Nevertheless, particularly in a girl, rapid growth between the years of 10 and 14 may be associated with alarming worsening of the curve, and of patients presenting in the scoliosis clinics the sex ratio tends to be about five girls to one boy.

The prognosis is variable and not always predictable. Again, from the findings of school screening programmes, very small curves-perhaps better thought of only as minor asymmetry of spine-may apparently undergo spontaneous resolution. Thus recent surveys have reported that between $3 \%$ and $22 \%$ of children examined with such asymmetry have undergone resolution or spontaneous improvement. ${ }^{12}$ The static nature of some minor "curves" may also be deduced from family surveys carried out in many centres in Britain, Europe, and North America-all of which have identified many adult relatives of both sexes who have had small curves that they were unaware of. ${ }^{3-5}$ Nevertheless, since it is impossible to determine which of these minor curves will progress and which will not, it is of the utmost importance that any child with this asymmetry should be carefully observed until she has stopped growing.

Considering only those curves which do progress, we have known for many years that the area of the spine in which the scoliosis develops and also the age of onset are important guides to prognosis. ${ }^{6}$ Untreated, all thoracic curves will become worse than lumbar ones, and the higher the thoracic curve the worse it is likely to be. Moreover, the younger the child when the curve starts, the worse the prognosis-the more years she has left to grow, the more years the curve has to become worse. Hence optimum treatment can be given only if the child presents early enough for this to be effective.

Methods of treatment adopted are usually some form of the Milwaukee brace, which alone may be effective in controlling or improving the curve. Scoliosis appearing at a young age (when many years of bracing may be thought undesirable for the child) and all severe curves are likely to require operative correction and fusion of the vertebrae in the area of the curve. The longer a curve has had to progress before effective treatment is undertaken, the more difficult it is to obtain other than minimal correction even by operation. This problem arises because, in addition to the lateral curvature of the spine, the vertebrae have also rotated, and the resulting conspicuous and ugly rib hump is difficult to improve.

On the other hand, a curve in the lumbar area is often small and unnoticed. The cosmetic defect is minor, and even untreated the curve does not usually become severe. The main problem here arises later, when backache develops in adult life owing to osteoarthritis of the intervertebral joints.

Clearly the onset of adolescent idiopathic scoliosis must be detected at the earliest possible moment, and school screening programmes for this purpose are becoming commoner in Britain. The child who has developed even a minor curve should be kept under review at about three-monthly intervals during the growing period so that progression can be detected immediately. There is some genetic component to the aetiology of this disorder, most writers favouring multifactorial inheritance, though some families appear to have a simple autosomal dominant type. Nevertheless, whatever the mode of transmission, some families are at a higher risk than normal of developing scoliosis, and hence all growing children in these families should be subjected to routine screening.

In Britain we are now more aware that adolescent idiopathic scoliosis exists, and many cases are diagnosed and referred to orthopaedic departments by general practitioners and school doctors. The block to effective management does not appear to be at this level. It is tragic that as recently as 1976, writing from the Edinburgh Scoliosis Clinic, James" stated: "A 'wait and see' policy based on ignorance of the behaviour of spinal curves is at present the biggest problem in the treatment of scoliosis. . . rarely is the initial diagnosis of scoliosis delayed, it is effective treatment that is withheld."

${ }^{1}$ Brooks, H L, et al, fournal of Bone and foint Surgery, 1975, 57A, 968.

2 Rogala, E J, Drummond, D S, and Gurr, J, fournal of Bone and foint Surgery, 1978, 60A, 173.

3 . Wynne-Davies, R, fournal of Bone and foint Surgery, 1968, 50B, 24.

4 Cowell, H R, Hall, N, and MacEwen, G D, Clinical Orthopaedics, 1972, 86, 121.

${ }^{5}$ Czeizel, A, et al, fournal of Medical Genetics, 1978, 15, 424.

6 James, J I P, fournal of Bone and foint Surgery, 1951, 33B, 399.

7 James, J I P, Scoliosis, 2nd edn. Edinburgh, London, and New York Churchill Livingstone, 1976. 